\title{
Observaciones sobre la peregrinación islámica delegada en los trabajos de Chardin, Niebuhr y Burckhardt (siglos XVII-XIX)
}

\author{
Observations on the \\ Islamic Pilgrimage by Proxy \\ in the Works of Chardin, Niebuhr, \\ and Burckhardt (1600-1900 AD)
}

\author{
SERGIO CARRO MARTÍN \\ Universidad Pompeu Fabra, España
}

Resumen: La peregrinación islámica delegada es una práctica conocida desde el siglo XI, cuando surgió una nueva tipología documental para acreditarla: los certificados de peregrinación a La Meca. Sin embargo, y a pesar de haber sido abordada en las principales obras legales suníes y si 'íes, todavía hay una gran carencia de fuentes que expliquen la burocracia desarrollada en torno a ella, especialmente entre los siglos XVII y XIX. Por el contrario, las obras publicadas por los viajeros europeos Jean Chardin, Carsten Niebuhr y Johann Ludwig Burckhardt aportan valiosa información sobre la delegación, obviada en estudios previos sobre la peregrinación islámica. Este

Recepción: 8 de noviembre de 2019. / Aceptación: 9 de septiembre de 2020. 
artículo busca arrojar luz sobre esta modalidad de peregrinación y la emisión de certificados mediante el análisis de diferentes extractos de los trabajos de estos tres viajeros.

Palabras clave: burocracia; certificados; viajeros europeos; islam; peregrinación.

Abstract: Records exist of Islamic pilgrimages by proxy since the beginning of the eleventh century thanks to the advent of a new typology of documents: pilgrimage certificates. However, and despite documentation in the main Sunnī and Shi' 1 legal works, there are still gaps in the sources that could help explain the bureaucracy that developed around this form of pilgrimage, especially between the seventeenth and nineteenth centuries. Conversely, three European travelers-Jean Chardin, Carsten Niebuhr, and Johann Ludwig Burckhardt-provide valuable information about pilgrimages by proxy overlooked by previous studies on Islamic pilgrimages. This article explores this form of pilgrimage and the issuance of certificates by analyzing different extracts from the works of these three travelers.

Keywords: bureaucracy; certificates; European travelers; Islam; pilgrimage.

\section{Introducción}

A pesar de que la peregrinación islámica es bien conocida en las fuentes árabes y ha sido tratada en numerosos estudios de carácter antropológico, político, social y religioso, todavía hoy plantea grandes incógnitas. La jurisprudencia y la burocracia desarrolladas en torno a ella son dos de sus aspectos menos documentados y analizados. Sin embargo, el avance en la catalogación y la digitalización de manuscritos nos permite ampliar el campo de trabajo en estos ámbitos. Los certificados de peregrinación delegada, tipología documental que en los últimos años ha ganado cierta atención entre los historiadores del Oriente islámico medieval, son uno de sus mejores exponentes, en la 
medida en que nos permiten adentrarnos en el cumplimiento de este precepto religioso desde el ámbito de la legalidad.

El tratamiento de la peregrinación islámica delegada ( $h a \hat{y} \hat{y}$ al-badal) en las fuentes árabes jurídicas, aunque limitado, ofrece una perspectiva del origen burocrático de estos documentos desde su aparición en el siglo XI. Diferente trayectoria parece haber seguido en las fuentes literarias, donde apenas encontramos menciones a la delegación de este precepto religioso y a los certificados que la acreditan. No sucede así en las obras de algunos viajeros europeos que visitaron Oriente entre los siglos XVII y XIX, como Jean Chardin (1643-1713), Carsten Niebuhr (1733-1815) y Johann Ludwig Burckhardt (1784-1817), cuyos relatos sobre la delegación y los certificados parecen haber pasado inadvertidos en los escasos estudios sobre esta modalidad de peregrinación y la documentación legal que generó.

El presente artículo reúne y analiza diversos fragmentos de las obras de estos tres viajeros, que considero esenciales en el estudio de la peregrinación delegada. En ellas se detallan las particularidades de esta práctica desde finales de la Edad Moderna, cuando la delegación parece haber caído en un aparente desuso, dada la escasez de certificados conservados durante ese periodo. Comenzaré detallando las particularidades de la peregrinación delegada y los certificados, lo que me permite ofrecer una panorámica sobre su origen legal en las fuentes árabes. A continuación, presentaré a los autores de las obras analizadas en este artículo, seleccionados para el estudio por la abundante información que ofrecen sobre el tema aquí tratado. Tomando como referencia su experiencia personal en Oriente, extraeré aquellos pasajes en los que se habla de la peregrinación delegada y analizaré sus principales conclusiones sobre dicha práctica.

\section{La peregrinación islámica delegada y los certificados}

Tal y como indica el Corán (3: 96-97), la peregrinación a La Meca es un deber prescrito únicamente para aquellos musulma- 
nes que dispongan de medios ( $\operatorname{man}$ istat $\bar{t}^{-} a$ ) para realizarla. Esta azora deja abierta la posibilidad a la denominada "capacidad indirecta”, por la que cualquier musulmán podía delegar su deber de peregrinar en una segunda persona (al-Gazālī 13561357/1937-1938, 447; Ibn Rušd 1302/1982, 319-320). Según los juristas musulmanes, la delegación era permisible cuando un musulmán quería llevar a cabo la peregrinación, pero no podía porque no contaba con la capacidad física para ello, o bien porque había muerto sin haber podido realizarla. En estos casos, el creyente podía pagar a otra persona para que peregrinara en su nombre.

Dicha práctica se documenta fundamentalmente en las obras de jurisprudencia islámica datadas entre los siglos XI y XIV. De ellas se extrae que esta modalidad de peregrinación generó una tipología documental específica, la de los certificados de peregrinación, que involucraba tanto al delegado como a su beneficiario. Con el fin de justificar el viaje y los gastos derivados de éste, el delegado debía aportar una prueba documental que acreditase la correcta realización de los rituales en nombre de su beneficiario (Carro Martín 2019, 148-150). Este documento, con formato de rollo, incluía una amplia descripción de los rituales, los nombres del delegado y el beneficiario y las firmas de varios testigos, así como ilustraciones de La Meca, Medina $y$, en ciertas ocasiones, Jerusalén.

La peregrinación delegada no debió haber sido habitual entre los peregrinos musulmanes, pues la mayoría de los certificados que se han conservado, procedentes de Siria, provienen de las clases más altas de su sociedad. El grupo más numeroso de certificados (en torno a unos doscientos), hallados en Damasco (Bauden 2005, 53; Radiciotti y D’Ottone 2008, 45-74), datan de los siglos XI a XIV y actualmente se conservan en la colección del Türk ve Islam Eserleri Müzesi, en Estambul (Sourdel y Sourdel-Tomine 1964, 1-25; 1983, 167-273; 2001, 212-233; 2006; Sourdel-Thomine y Mouton 2018a, 507-523; 2018b, 3-29). Fuera de esta colección, únicamente se han documentado menos de una decena de ejemplares entre las principales colec- 
ciones orientales (Reinaud 1828, 312-324; Tanindi 1983, 2-6; Esin 1983, 175-190), por lo que llama la atención el desinterés que desde mediados del siglo XVI parecen haber acusado los certificados de peregrinación entre los viajeros musulmanes. Se tiene registro de nuevos certificados a comienzos del siglo XVIII, y de una particular abundancia de ellos a finales del siglo XIX, momento en el que parecen haber resurgido como souvenirs del viaje realizado (Mols 2015, 185-212; Moufahim 2013, 421-441).

Este lapso en la emisión de certificados por las autoridades de La Meca no parece haberse documentado en las fuentes árabes, las cuales, por el contrario, sólo referencian la práctica de la delegación durante los primeros siglos del islam. Tampoco parece ser mencionada en los relatos de viaje (ribla) de conocidos viajeros musulmanes, ni en las obras de género biográfico (sìra), histórico o de tipo religioso (Eickelman y Piscatori 1990). Sin embargo, como muestro a continuación, puede verse complementada por las descripciones que encontramos en los relatos de algunos viajeros occidentales que entre los siglos XVII y XIX se adentraron en la cultura y la religión islámicas árabes y persas.

\section{Arabia y los viajeros europeos}

La lista de viajeros occidentales que visitaron Arabia desde el siglo XV es muy amplia, aunque no todos pusieron por escrito su experiencia o lo hicieron con la misma minuciosidad descriptiva. Las principales diferencias en sus relatos radican, precisamente, en la perspectiva adoptada, pues en algunos casos son auténticos libros de viaje y, en otros, amplios estudios etnográficos. En este sentido, el repertorio textual seleccionado para este artículo se ha reducido a una obra y un viajero por siglo, con lo que se cubre el espectro temporal que abarcan los siglos XVII, XVIII y XIX. Este rango cronológico es el mismo en el que parece documentarse un ligero repunte en la producción de certificados, por lo que cualquier descripción alusiva 
a estos materiales supone un complemento indispensable para el conocimiento de la burocracia de la peregrinación delegada en el islam.

Hay constancia de la presencia de viajeros occidentales en Arabia desde comienzos del siglo XVI, cuando el italiano Ludovico de Varthema (1470-1517) consiguió llegar a La Meca haciéndose pasar por musulmán. Su experiencia animó a otros viajeros a visitar Arabia, habitualmente como parte de expediciones científicas en las que participaban etnógrafos, biólogos, médicos y cartógrafos. En otros casos, fue el afán de descubrimiento de lugares remotos lo que los llevó a visitar Oriente. Movidos por el interés que suscitaba en Europa cualquier información sobre Arabia, otros viajeros dejaron constancia escrita de su periplo por aquella región. En sus trabajos describen su paso por los principales lugares santos del islam, las costumbres musulmanas, la peregrinación y los rituales asociados a ella (Peters 1994, 206-257).

Lejos de abordar este material desde una perspectiva orientalista, sus relatos recogen de primera mano las prácticas asociadas a la peregrinación islámica, aunque no todos ofrecen en sus descripciones información sobre la delegación o la emisión de certificados que la acreditaran. Éste es el caso de viajeros como Johann Wild, que llegó a La Meca en 1607; Joseph Pitts, quien presumió de haber sido el primer inglés en entrar a la Ka'ba en 1680; Domingo Badía y Leblich en 1806, más conocido como Ali Bay; Ulrich Jasper Seetzen en 1809; Giovanni Finati en 1814; Léon Roches en 1841; George Augustus Wallin en 1845 o Richard Burton en 1853, entre otros. ${ }^{1}$ Sí lo hicieron los ya mencionados Jean Chardin, Carsten Niebuhr y Johann Ludwig Burckhardt, cuyos trabajos analizo a continuación. ${ }^{2}$

${ }^{1}$ En la segunda mitad del siglo XIX cabría mencionar a Heinrich Freiherr von Maltzan, Herman Bicknell, John Fryer Keane o Christiaan Snouck Hurgronje (Ralli 1909).

${ }^{2}$ Los extractos que se exponen a lo largo del siguiente epígrafe han sido tomados, cuando ha sido posible, de las primeras ediciones de sus obras. En ellas el lector podrá comprobar numerosas discrepancias respecto de la transcripción de términos árabes, los cuales he querido mantener en la traducción al español que presento. Lamenta- 


\section{Jean Chardin (1643-1713)}

Jean Chardin fue un comerciante parisino que viajó a Persia e India en 1665. En su viaje contactó con el šăh Abbās II (r. 16421666), quien lo nombró su marchante de joyas. Regresó a Francia en 1670 y un año más tarde volvió a Persia. Allí permaneció una década, y después se estableció definitivamente en Inglaterra hacia 1680. En calidad de representante de la Compañía Británica de las Indias Orientales viajó a Holanda, donde en 1686 publicó la primera parte de su obra Voyages de monsieur le chevalier Chardin en Perse et autres lieux de l'Orient [Viajes del señor caballero Chardin en Persia y otros lugares de Oriente] (Chardin 1711). El encargado de su edición fue Louis-Mathieu Langlès, quién la recopiló en 10 volúmenes. En ellos, Chardin trataba toda clase de aspectos sobre los persas y la religión islámica.

Aunque Chardin no visitó las ciudades de La Meca y Medina, su experiencia y su contacto con el mundo musulmán le otorgaron un amplio conocimiento de las prácticas y los rituales de la peregrinación (Katz 2004, 95-129). Bajo el epígrafe "Description de la religion. Du pèlerinage" [Descripción de la religión. Sobre la peregrinación], Chardin describe los rituales que deben llevarse a cabo en La Meca para obtener el título honorífico de peregrino (hâŷyz) con el que los viajeros eran distinguidos, no sin antes mencionar que los persas difieren de otros pueblos musulmanes en el deber de acometer este precepto religioso (Chardin 1711, 436).

En opinión de Chardin, los persas interpretaban la obligación de peregrinar a La Meca de una manera menos estricta que los turcos, ya que éstos contemplaban la delegación de la peregrinación en muchos más casos de los que recogen tanto los autores orientales (al-Gazālī 1356-1357/1937-1938, 447) como los andalusíes (Ibn Rušd 1302/1982, 320). Según Chardin,

blemente, no parecen haberse conservado ejemplares de los certificados mencionados por estos viajeros. 
los persas no entendían la peregrinación como una obligación cuando, a pesar de gozar de salud, el creyente no podía asumir económicamente el viaje. Del mismo modo, si tenía dinero, pero no salud, tampoco estaba obligado a peregrinar; en los dos casos, le era permitido encomendar su peregrinación a una segunda persona.

Este relato supone la primera mención que tenemos de la peregrinación islámica delegada en una obra occidental. Como se verá a continuación, Chardin expone que la peregrinación se compraba a alguien que ya la había realizado, tal como prescribe el derecho islámico (Jalīl b. Ishạāq 1848, 12; al-Mișrī 1994, 305; Muhaqqiq al-Hillī 1871, 226-233). Según su descripción, se trataba de una actividad que parecía habitual en Persia, e incluso llegaba a considerarse un trabajo al uso:

Los persas, por el contrario, dicen que el precepto no debe tomarse literalmente, sino con modificación, y que los imames, que son los primeros sucesores de Muhammad, han declarado que la obligación de la peregrinación no es solamente para aquellos que están en perfecto estado de salud; que hacen bien en pagar sus deudas, proporcionar la dote de sus esposas, dar a su familia un año de subsistencia, dejar algo para volver a su oficio o negocio a su retorno y en quitar, después de todo esto, quinientas coronas en efectivo para los gastos del viaje. Que si no se tienen estos medios no están obligados a peregrinar, y si los tienen, pero no tienen la salud que se necesita, deben hacer la peregrinación mediante su delegación, lo que se hace comprando la peregrinación a alguien que ya la hizo. Hay muchos árabes por toda Persia que viven de estas peregrinaciones (Chardin 1711, 433-434).

Como vemos, Chardin indica que antes de realizar la peregrinación era imprescindible tener la seguridad de que los allegados, esposa e hijos del peregrino (en el caso de que fuera un hombre), estarían bien atendidos y no tendrían ninguna necesidad en su ausencia. Se trata de un hecho al que ya habían apuntado diferentes juristas, como recoge Ibn Rušd (1302/1982, 320). En otro de los pasajes, Chardin manifiesta, además, que los peregrinos adquirían actas emitidas por el jerife de La Meca, denominadas ziaret namé o certificados del viaje de devoción, 
en los que se exponía la visita a los lugares santos de acuerdo con lo establecido por el derecho islámico.

Los certificados debían entregarse a quien había encomendado la peregrinación o a quien había comprado el viaje. Esta diferencia no es explicada por Chardin, por lo que se deduce que, además de comprar este servicio, había peregrinos que efectuaban el viaje solamente por devoción, sin percibir dinero por ello. Chardin también registra el precio que se pagaba por este tipo de peregrinación: entre setecientos y mil francos, según el poder adquisitivo del beneficiario, cantidad que se fijaba en un contrato hecho delante de jueces civiles, como se hacía con cualquier otro asunto:

Reciben del jerife de La Meca y de otras personas eminentes del lugar actas llamadas ziaret namé, es decir, certificados de viajes devocionales, que indican que visitaron los lugares sagrados y practicaron toda la justicia legal de la peregrinación, los actos que realizaron, el nombre de quien fue enviado o quien compró su viaje: el precio suele ser entre setecientos y mil francos y el contrato se realiza ante uno de los jueces civiles, al igual que otras cuestiones. Un persa no podría hacer convenientemente este viaje desde Isfahan, ya que le costaría cincuenta tomans, ${ }^{3}$ lo que equivale a unos doscientos louïs de oro: ${ }^{4}$ hay personas que gastan hasta cien mil, porque el espíritu de la peregrinación quiere que se gaste de acuerdo con sus medios, e implican a mucha gente y dejan grandes limosnas en el camino (Chardin 1711, 433-434).

El texto continúa con la narración acerca de un hombre que muere sin haber hecho la peregrinación, pero que deja en su legado una cantidad suficiente para ello. Según Chardin, en esta situación, la autoridad jurídica tomaba una parte del recurso para que se hiciera un viaje en nombre del difunto, y su cuerpo no se consideraba purificado hasta que el juez civil confirmara que el delegado había realizado la peregrinación, de lo cual presuponemos el uso de uno de estos certificados:

${ }^{3}$ Divisa acuñada en Irán entre el siglo XVII y comienzos del siglo xx.

${ }^{4}$ El luis de oro fue un tipo de moneda de oro emitida en Francia a partir del reinado de Luis XIII, desde 1640 hasta 1792. 
Si un hombre muere sin haber hecho esta peregrinación, ni en persona ni a través de un delegado, pero deja bastantes bienes para hacerlo, el magistrado eclesiástico o civil asume la autoridad legal para hacer este viaje en nombre del difunto, para descanso de su nombre. He observado anteriormente que en Persia es imposible administrar a un cuerpo muerto la purificación habitual del entierro sin conocer el permiso del $k a d y,{ }^{5}$ que es el juez civil. Nunca lo otorga sin saber si el difunto ha realizado la peregrinación, y si encuentra que no estaba allí, o que no había enviado (a alguien), independientemente de los medios que tuviera para ello, se deposita en sus manos la suma necesaria para realizar esta peregrinación en nombre del difunto, antes de permitir su sepultura (Chardin 1711, 433-434; cf. Muhaqqiq al-Hillī 1871, 223, 228-230).

A pesar de la escasez de ejemplares conservados de ese periodo, parece que la adquisición de certificados que atestiguan la visita a los lugares santos fue habitual entre los peregrinos musulmanes también durante el siglo XVII. Según Chardin, antes de regresar a sus casas, muchos musulmanes se hacían con estos documentos, que eran expedidos por las autoridades de La Meca. Indica que el gardien de la Chapelle (es decir, "el imam de la mezquita”) emitía el certificado y, sobre éste, el jerife estampaba su sello, confirmando así el carácter oficial del servicio. También lo hacían los magistrados (es decir, notarios profesionales), así como aquellos a los que Chardin denomina "personajes eminentes" del lugar.

El texto que contenían los certificados mencionaba la realización de la peregrinación y el nombre del peregrino, así como largas bendiciones, tal como reflejan los certificados de peregrinación documentados entre los siglos XI y XV. Chardin no indica, sin embargo, si en ese texto se mencionaba el nombre del beneficiario, lo que deja abierta la posibilidad de que se tratara de certificados personales y no por delegación. Añade que, cuando los peregrinos volvían a sus lugares de origen, llevaban los documentos a las mezquitas o a las tumbas de los santos musulmanes, a modo de exvoto:

${ }^{5}$ Qādìi: juez o magistrado musulmán. 
La mayor parte de los peregrinos disponen antes de su partida de un acta de su peregrinación, que Moutevely, el regente gardien de la Chapelle, hace expedir: el jerife pone su sello, y los magistrados y los personajes más eminentes que se encuentran en el lugar ponen después el sello de la mezquita, que suele ser grande como la palma de la mano y que contiene las palabras del Corán, o los Dichos de los Santos. Estas actas se llaman, como he dicho, ziaret namé, es decir, acta del viajero, del verbo zar, que significa "viajar", "ir al país", y también "aoulia"; ${ }^{6}$ son largos y de media vara, y contienen el año en que se ha hecho su peregrinación; después de esto hay largas bendiciones. Muchas personas depositan estos certificados, cuando regresan a sus casas, en las mezquitas o en las tumbas de los santos, donde los ponen a modo de exvoto. Desde La Meca uno suele ir a Medina para visitar la tumba de Mohammed. Ésta es una peregrinación que es sólo por devoción, no es obligatoria (Chardin 1711, 435).

También destaca que los peregrinos visitaban la mezquita del profeta en Medina, tras lo cual tomaban la correspondiente ruta a través de Bagdad, donde visitaban las tumbas de los imames sí íes. Las paradas se realizaban en diferentes ciudades de Iraq, como Karbalā', donde los peregrinos adquirían nuevamente certificados que atestiguaban su visita: "Desde Medina, los peregrinos persas toman su ruta hacia Bagdad y visitan las tumbas de sus imames, que se encuentran en Bakié, en Hellé, en Kerbella, en las desoladas zonas rurales de Chaldée y cerca de Bagdad: todos se hacen con actas de su peregrinación" (Chardin 1711, 436).

Este tipo de visitas también pueden documentarse en el siglo XVI, gracias a los escasos ejemplares que se han conservado y que atestiguan visitas personales a santuarios de Iraq e Irán. ${ }^{8}$ Los certificados a los que alude Chardin bien podrían

${ }^{6}$ Probablemente se refiere a la extensión (en árabe, tawĩl) del rollo, que menciona después.

${ }^{7}$ Es decir, Caldea, zona extrema sudoriental de la parte meridional de la cuenca del Éufrates y el Tigris, próximo a los desiertos de Arabia.

${ }^{8}$ Entre ellos, cabría destacar el certificado persa AKM 899 (1522) de la colección Aga Khan. El documento certifica la peregrinación de un individuo al santuario del imam al-Riḍa en Mašhad. En la parte inferior, un sello de la mezquita valida el documento (Graves y Junod 2011, 46-47). 
ser ejemplares como los de Kailua, en Hawái (Marzolph 2014, 207-242), la Universidad de Lund, en Suecia (Hjärpe 1998, 197-204), o el certificado publicado por el misionero Samuel Zwemer (1867-1952) en 1900 (Zwemer 1900, 40; Adams 1900, 396-405). Se trata de certificados estampados con ilustraciones muy similares dedicadas a La Meca, Medina, Jerusalén y los principales lugares santos ši 'íes, todos ellos datados entre los siglos XVIII y XIX.

\section{Carsten Niebuhr (1733-1815)}

Carsten Niebuhr nació en Lüdingworth, la baja Sajonia, en 1733. Se formó como matemático, lo que le valió su trabajo como ingeniero de navegación al servicio de Dinamarca. En 1761, uno de sus profesores le propuso unirse a la expedición geográfica que estaba patrocinando el rey Federico V de Dinamarca para explorar Egipto, Arabia y Siria. Durante ese viaje visitó las ciudades santas de Medina y La Meca, y más tarde Yemen.

A su regreso, una década después, Niebuhr publicó un libro de corte etnográfico titulado Beschreibung von Arabien [Descripción de Arabia], en el que recopiló diferentes datos sobre el viaje. En la obra encontramos varias líneas dedicadas a los lugares santos de La Meca y Medina, y a los rituales de la peregrinación y el comercio de la zona. Niebuhr comenta las dificultades de los cristianos para visitar el santuario, que "no se atreven a entrar en La Meca" debido a los prejuicios de los musulmanes (Niebuhr 1792, 32). Por este motivo, la descripción que hace del santuario se basa en las ilustraciones ${ }^{9}$ que circulan entre los peregrinos:

${ }^{9}$ Burckhardt $(1829,162)$, de quien hablaremos más adelante, comentó en una nota que las descripciones de Niebuhr se basaban, efectivamente, en una ilustración que había comprado, y que no eran del todo correctas. Sin embargo, Niebuhr se limitó a describir lo que había sido representado en la ilustración. 
Yo incluso obtuve en Kabira ${ }^{10}$ un dibujo de ese lugar sagrado que luego tuve la oportunidad de corregir de otro borrador de un pintor turco. Este pintor se ganaba la vida haciendo tales ilustraciones de la $K a b a^{11}$ que vendía a los peregrinos [...]. A juzgar por estos diseños y por los relatos de muchos musulmanes de veracidad incontestable, la Kaba debe ser un edificio basto y sin forma, una fortaleza con una torre cuadrada cubierta en la parte superior con un pedazo de seda negra bordada en oro (Niebuhr 1792, 33-34).

A su llegada a La Meca, Niebuhr conoció a un pintor turco que le ayudó a corregir la ilustración que había adquirido en El Cairo. Niebuhr fue pues testigo de cómo los artistas musulmanes realizaban ilustraciones de la Ka'ba que luego vendían a los peregrinos. Por lo tanto, del texto se extraen dos importantes datos: en primer lugar, las ilustraciones sobre los lugares santos se producían y comercializaban no sólo en La Meca, sino también en otras ciudades, como El Cairo. En este sentido, cabe mencionar que el propio Niebuhr adquirió asimismo un rollo ilustrado cuando visitó la tumba del imán Husayn en Mašhad, que actualmente se conserva en el Departamento de Etnografía del National Museum of Denmark, en Copenhague (Marzolph 2017, 69-73). Este rollo demuestra que las ilustraciones y los certificados también se comercializaban en Irán e Iraq. En segundo lugar, del testimonio de Niebuhr se desprende que en La Meca trabajaban ilustradores procedentes de otros lugares. En este caso, el artista al que recurrió para corregir la imagen adquirida en El Cairo era de origen turco.

También es llamativo el uso del plural cuando hace referencia a esos trabajos: "A juzgar por estos diseños", lo que indica que no se trataba de piezas ocasionales, sino de ilustraciones frecuentes en los mercados o vendidas a las puertas de los santuarios. Así, tan sólo unos párrafos después, nos informa que los mercaderes, muchos de los cuales acompañaban a las caravanas,

${ }^{10}$ El Cairo.

${ }^{11}$ Se refiere a la Ka'ba. 
"exponen sus objetos para venderlos bajo las arcadas" (Niebuhr 1792, 35-36). Se refiere a los pórticos de los santuarios de La Meca y Medina donde ofrecían un buen número de artículos a los peregrinos. Sus descripciones van en la misma línea que las de otros viajeros, como Varthema, Burton o Buckhard, quienes hablan de numerosos vendedores debajo de los arcos de ambos santuarios.

El interés de Niebuhr por la religión islámica queda también patente en sus comentarios sobre el aspecto legal de la peregrinación y los supuestos en los que un musulmán podía encomendarla a otra persona. En su opinión, la gran cantidad de peregrinos que anualmente visitaban La Meca se debía a la posibilidad de delegar dicha obligación:

Es sabido que todo musulmán está obligado, una vez en su vida, a visitar La Meca y a realizar actos de devoción en los lugares sagrados. Si esta ley se cumpliera estrictamente, el grueso de los peregrinos que la visitan no sería tan inmenso ni la ciudad podría contener tales multitudes de todos los países en los que se ha introducido la religión mahometana. Por lo tanto, se puede presumir que nadie más que los devotos cumplen con este deber. Aquellos, de hecho, cuyas circunstancias no les permitieron emprender este largo viaje, pueden contratar a un delegado para que lo haga por ellos (Niebuhr 1792, 36-37).

Como vemos, Niebuhr recoge la posibilidad de que una persona pueda realizar la peregrinación en nombre de otra cuando esté impedida, o cuando hubiera descuidado el cumplimiento de este deber en vida. Deja claro que, en este caso, el beneficio de la peregrinación es para esta persona y no para quien físicamente realiza dicho viaje y cumple con los rituales requeridos (su delegado).

La exposición que Niebuhr hace de la peregrinación continúa con la descripción de los denominados peregrinos "profesionales", que él mismo encontró en su viaje. De sus palabras se extrae que fue una práctica común entre los habitantes de los lugares santos ofrecerse como delegados de la peregrinación, por lo cual cobraban altas cantidades. Sin embargo, esta 
actividad fue reprobada por las autoridades de La Meca, y para controlarla emitieron los certificados de peregrinación:

Un peregrino, en este papel, no puede actuar por más de una persona al mismo tiempo y, para evitar la impostura, debe traer de vuelta un testimonio formal de un imam de La Meca que indique que ha realizado los rituales devocionales designados en los lugares santos en nombre de una persona, viva o muerta. Porque incluso después de la muerte de un hombre que durante su vida descuidó el cumplimiento de este punto de la ley, el deber aún puede ser cumplido en su nombre y para su beneficio. A veces me he encontrado con peregrinos profesionales que habían sido mal pagados por sus empleadores, y estaban obligados a pedir limosna. Son sólo unos pocos en proporción a los numerosos musulmanes de la caravana, incluso aquellos grupos que están, en gran parte, compuestos por personas que van únicamente por motivos distintos a la devoción, como los comerciantes, que piensan que ésta es la oportunidad más segura para transportar sus productos y la forma más favorable para venderlos (Niebuhr 1792, 35-36).

Del relato de Niebuhr se deduce que los certificados de peregrinación fueron, además, una forma de favorecer la peregrinación y propiciar el desarrollo económico de La Meca. Con ello se lograba mantener el flujo constante de peregrinos y se evitaba que una sola persona llevara a cabo la peregrinación por varias al mismo tiempo. El relato de Niebuhr constituye la primera noticia que se tiene sobre una función adicional de este tipo de documentos, y sobre el ejercicio de la delegación como una profesión más.

Este oficio habría surgido como una solución a los requerimientos legales de la peregrinación delegada, que, como se ha visto, sólo podía llevarse a cabo cuando el delegado ya había realizado su propia peregrinación. En consecuencia, el surgimiento de peregrinos profesionales habría propiciado que los musulmanes que llegaban a La Meca por primera vez pudieran volver a su hogar con un certificado de peregrinación en nombre de otra persona, además de haber realizado la propia. En cualquier caso, parece claro que solamente después de haber llevado a cabo los rituales, el peregrino podía obtener 
el título de peregrino. Se trata de un título honorífico que no se debe confundir con los certificados antes mencionados, expedidos únicamente en aquellos casos en los que el beneficiario de la peregrinación era una segunda persona (cf. Niebuhr 1792, 39).

Niebuhr también relata cómo los musulmanes - principalmente los que formaban parte de la caravana siria- visitaban la mezquita del profeta en Medina, y aclara que no se trataba de una práctica obligada sino devocional: "La tumba de Mahoma en Medina es respetada por los musulmanes, pero no están obligados a visitarla como cumplimiento de ningún ejercicio devocional; sólo cuando las caravanas de Siria necesariamente pasan cerca de Medina, a su regreso de La Meca, se apartan para contemplar la tumba del Profeta" (Niebuhr 1792, 40).

De nuevo, Niebuhr hace uso de una ilustración para describir el santuario. No queda claro si obtuvo tal dibujo en Medina, pero sí que se trata de un manuscrito diferente al que mencionó antes y que portaba una imagen del santuario de La Meca:

También obtuve de un turco un dibujo de la mezquita con la tumba. Está situada en una esquina de la gran plaza, mientras que la Kaba está en medio de una plaza en La Meca. Por temor a que la gente ofrezca supersticiosamente la adoración a las cenizas del Profeta, la tumba está encerrada dentro de barras de hierro, y sólo se puede ver si miras a través de ellas. Es un simple trabajo de albañilería, en forma de cofre, y esto es todo el monumento (Niebuhr 1792, 40-41).

De su relato se desprenden varias cuestiones: la primera es que, además de ilustraciones de La Meca, también circulaban imágenes de la mezquita del Profeta en Medina. Por otra parte, menciona que la ilustración que adquirió también fue vendida (y quizás hecha) por un turco. Gracias a su relato sabemos que esta ilustración mostraba correctamente la mezquita del Profeta en una de las esquinas del santuario. Se ignora, sin embargo, si las ilustraciones de Medina contenían algún texto que pudiera hacer pensar que las autoridades del santuario también emitían 
certificados de su visita (ziyāra), hecho que parece probable si tenemos en cuenta algunos de los ejemplares conservados. ${ }^{12}$

\section{Johann Ludwig Burckhardt (1784-1817)}

Johann Ludwig Burckhardt fue un explorador suizo nacido en Lausana, profundo conocedor de la lengua árabe y de la religión islámica que, haciéndose pasar por un mercader árabe, viajó por Oriente Próximo y Nubia. En 1806, después de estudiar en las universidades de Leipzig y Göttingen, viajó a Inglaterra. Allí consiguió un empleo en la Asociación Africana, que por entonces planeaba organizar una expedición para descubrir las fuentes del río Níger. Burckhardt se preparó para el viaje y asistió a la Universidad de Cambridge, donde estudió árabe.

Abandonó Inglaterra en marzo de 1809 y en el otoño llegó a Alepo, en Siria. Se hizo pasar por musulmán y tomó el nombre de Ibrāhīm b. 'Abd Allāh. Años más tarde cruzó el mar Rojo y, finalmente, en 1814 entró en La Meca. Allí pasó varios meses realizando los diversos rituales asociados con el haŷy. También hizo un viaje a Medina, tras el cual viajó a El Cairo, donde murió el 24 de junio de 1817.

En su viaje por Arabia, Burckhardt escribió en sus diarios observaciones detalladas sobre ambas ciudades, el comportamiento y la cultura de sus habitantes, pero sobre todo acerca de los cargos y las instituciones que regulaban la peregrinación en La Meca (cf. Hawting 1990, 62-84). Al igual que Niebuhr, Burckhardt menciona en sus escritos que, para que la peregrinación se considerara válida, era completamente necesario que el peregrino realizara correctamente todos los rituales exigidos. Tampoco le acreditaría como peregrino el haber visitado los lugares santos si antes no había asistido a lo que denomina "Khotbet el Wakfe", ${ }^{13}$ es decir, si no había realizado

12 Por ejemplo, el certificado con número de inventario plano 53 F 1, núm. 58, conservado en la Biblioteca Universitaria de Leiden (Witkam 2009, 27-32, fig. 7).

${ }^{13}$ Literalmente, "el sermón de la pausa". 
el ritual del wuqüf (lit. "pausa") que tiene lugar en el monte 'Arafāt (Burckhardt 1829, 1: 48).

$\mathrm{Su}$ experiencia en La Meca lo llevó a afirmar que, aunque la ley islámica marcaba minuciosamente los pasos que el peregrino debía seguir, en la práctica apenas unos pocos podían presumir de haber ejecutado correctamente estos ritos. Según su relato, era común que los peregrinos cumplieran de manera superficial con los deberes que la religión islámica les imponía. Curiosamente, Burckhardt achaca esto a la inexistencia de una policía que hiciera cumplir los rituales prescritos:

La ley hace tantas distinciones e incrementa tanto el número de reglas que deben guiar al peregrino en cada paso, que muy pocos pueden atribuirse la facultad de ser hadjys ${ }^{14}$ regulares; pero, ya que no hay ningún policía que vigile los rituales durante la ceremonia, cada uno es completamente su propio maestro y asume el título de hadjy, haya o no cumplido estrictamente todos los deberes. Para ello es suficiente que hayan estado en Arafat en el día apropiado; ésta es la única distinción, pero una mera visita a La Meca no autoriza a un hombre a denominarse a sí mismo hadjy y la apropiación de este título sin más pretensiones lo expone al ridículo (Burckhardt 1829, 2: 75-76).

El título de haŷyza al que alude Burckhardt es una designación empírica para definir únicamente a quienes han realizado la peregrinación. Sin embargo, el simple hecho de ser peregrino implicaba una consideración especial que llevaba al viajero a ser respetado allá donde estuviere (Burckhardt 1829, 2: 16). Según sus anotaciones, la gente pudiente de La Meca compraba dibujos o ilustraciones de la ciudad, a las cuales anexaban una certificación firmada por cuatro testigos. En ella confirmaban que el comprador había hecho la peregrinación. Esta información puede relacionarse con el relato de Niebuhr, que, como hemos visto, también documentó la venta de ilustraciones de los lugares santos. De las palabras de Burckhardt se puede presuponer que aquellas ilustraciones eran certificados de peregrinación. Sin embargo, y contrariamente a lo indicado por Chardin o

${ }^{14}$ Haŷŷ̀ (peregrino). 
Niebuhr, Burckhardt indica que no eran documentos emitidos por las autoridades de La Meca, pero que sí estaban validados por cuatro testigos: "No hay ningún documento formal otorgado a los hadjys en La Meca, como en Jerusalén, pero gran parte de la gente compra algunos dibujos de la ciudad junto a los cuales hay anexado el testimonio de cuatro testigos que indica que los compradores eran peregrinos" (Burckhardt 1829, 2: 76).

Entre los peregrinos que viajaban a La Meca, Burckhardt también distingue a aquellos que lo hacían para llevar a cabo la peregrinación en nombre de otra persona. Según su relato, el coste de su viaje era asumido por el beneficiario de la peregrinación. A pesar de ello, parece que muchos de los peregrinos necesitaban mendigar para asumir el coste del viaje de vuelta a sus lugares de origen:

Multitud de mendigos vienen a La Meca desde los países antes mencio-
nados; obtienen un pasaje gratuito de individuos piadosos en su pro-
pio país, o, en su caso, el coste es sufragado por quienes los emplean
como sus delegados en la realización del Hadj ${ }^{15}$ pero cuando llegan son
arrojados enteramente a la caridad de otros peregrinos, y las limosnas
que recogen les sirven para llevarlos de regreso a sus hogares (Burckhardt
1829, 2: 20-21).

Burckhardt también comenta algunas de las prácticas que habitualmente se daban en la entrada del santuario de La Meca. Al igual que otros viajeros europeos, como los mencionados Varthema o Niebuhr, Burckhardt fue testigo de la ferviente actividad comercial en la entrada norte del santuario, especialmente en las inmediaciones de la Puerta de la Paz (Bāb al-salām), donde muchos vendedores instalaban sus puestos (Burckhardt 1829, 1: 327-328). Pero lo más interesante de su relato es la alusión que hace a uno de ellos. Allí, Burckhardt encuentra ilustraciones de La Meca y Medina hechas sobre papel grueso o de lino, con colores vistosos, además de oraciones impresas y otros objetos: "En la misma tienda se venden dibujos de $\mathrm{La}$

${ }^{15}$ Hâŷy (peregrinación). 
Meca y Medina, realizados en un estilo tosco y llamativo, hechos sobre papel o lino, y pequeñas impresiones de oraciones, etc., procedentes de grabados sobre madera. Compré algunos de éstos con el mismo propósito que las botellas del zemzem ${ }^{16}$ que tomé de aquí" (Burckhardt 1829, 1: 328).

En otro pasaje, Burckhardt destaca el trabajo diario de algunos jeques (šayj) que diariamente se instalaban cerca de Bāb al-salām provistos de papel y tinta con la que escribían diferentes documentos a petición de los peregrinos. Pero, además, menciona que estos jeques vendían escritos que eran usados con distintos fines. Entre ellos había amuletos que eran solicitados principalmente por los beduinos, a los que, según Burckhardt, se les cobraba un precio desmedido:

Cerca de la puerta de la mezquita llamada Bab-es-Salam, algunos jeques árabes toman asiento diariamente, con sus tinteros, cartas, cuentas, contratos o cualquier otro documento similar. También se ocupan de encantamientos escritos, como los que hay en los países negros, ${ }^{17}$ como amuletos y recibos de amor, llamados "kotob mubbat" o "kuboul". Son empleados principalmente por beduinos y exigen una remuneración exorbitante (Burckhardt 1829, 1: 376-277).

Como se puede ver, lo que Burckhardt se encontró a las puertas de La Meca fue una intensa actividad comercial propiciada por el flujo incesante de peregrinos que llegaban al santuario. Con su relato, nos confirma que en La Meca se practicaban diferentes oficios (Burckhardt 1829, 2: 76-77) y que había mercaderes cuyos productos se dirigían a los peregrinos. Entre los oficios destaca el ejercido por escribas y copistas profesionales, que también se puede documentar durante el siglo XII, a través, por ejemplo, del relato de Ibn Ŷubayr (2007, 116-117).

${ }^{16}$ Zamzam. Pozo de agua que se encuentra a escasos metros de la Ka'ba y al que los musulmanes atribuyen propiedades beneficiosas para la salud, y cuya agua beben durante los rituales de la peregrinación.

${ }^{17}$ Probablemente se refiere al territorio de Sudán, cuyo nombre deriva del término árabe aswad (negro). 
Según Burckhardt, muchos de los escribas que se encontraban a la entrada del santuario eran líderes religiosos locales que redactaban contratos y textos jurídicos, por lo que parece evidente que contaban con conocimientos en jurisprudencia islámica. En tal caso, estos escribas estarían habilitados para ejercer sus funciones como redactores de documentos legales, como los certificados de peregrinación a los que aludían Chardin y Niebuhr (Niebuhr, 1792, 36-37).

Queda claro, por tanto, que el oficio de estas personas contemplaba temas muy variados que incluían la elaboración de documentos legales, amuletos y oraciones. ${ }^{18}$ También se debe destacar que, entre los productos ofrecidos, fuera posible adquirir ilustraciones de ambos lugares santos, conforme al estilo de los certificados de peregrinación medievales.

\section{Conclusiones}

Como se ha podido comprobar, los textos analizados aportan innumerables datos sobre el ejercicio de la peregrinación subrogada y su relación con los certificados emitidos en La Meca. Son materiales que nos ofrecen una imagen institucionalizada y, por lo tanto, burocratizada de la peregrinación delegada, que no parece documentarse en las fuentes árabes, donde sólo es tratada desde un punto de vista legal y no procedimental. Gracias a estos relatos he podido confirmar la pervivencia de dicha modalidad de peregrinación en un periodo (siglos XVI-XIX) materialmente marcado en un reducido legado documental.

A pesar de esta carencia, se puede concluir que los certificados continuaron siendo expedidos y que en ellos se adoptaron

${ }^{18}$ Se han conservado varias planchas de metal con ilustraciones de los lugares santos que fueron utilizadas para producir copias en papel. El texto que acompaña a las ilustraciones habla de las características físicas del profeta Muhammad (ḅilya) y recoge diferentes versos coránicos y hadices. The Walters Art Museum conserva una de estas planchas (Inv. 54.510, siglo xvIII, catalogada como certificado de peregrinación) y en la colección Khalili, uno de los estampados en papel (CAL 482, siglo XIX). 
los mismos patrones de formulación textual recogidos en los primeros ejemplares conocidos (siglos XI-XV). Más aún, gracias a sus descripciones es posible conocer el mecanismo administrativo que operaba en la emisión de certificados, en el cual las autoridades religiosas de La Meca, como el jerife, los jueces locales y los notarios, intervenían para su validación.

A este respecto, resulta especialmente llamativo el relato de Chardin, en cuya narración presta especial atención a la cuestión administrativa de los persas. Su interés lo lleva a describir el complejo sistema legal islámico de la peregrinación delegada, para incidir en la necesidad de diferenciar entre la observancia que los persas hacen de este precepto y la forma en que la delegación es concebida por los otomanos. Lo más significativo de su descripción es la confirmación de que los árabes (y no sólo los persas) hicieron de este acto devocional un trabajo profesional y remunerado, lo cual fue más tarde confirmado por Burckhardt. Describe, además, cómo los contratos entre el beneficiario y el peregrino eran realizados ante un juez civil por un precio previamente acordado, tal como lo mencionan los formularios notariales de los siglos XI y XII (Ibn al-'Ațtār 2000, 699; cf. con al-Ŷazīrī 1998, 365-366).

Igual de significativa es la presencia en el certificado de un sello propio de la mezquita que corrobora la validación del documento por medio de los notarios y, por tanto, la burocratización del procedimiento, desconocido hasta la fecha. Dicha práctica, según Niebuhr, parecía estar asociada al hecho de que los peregrinos solamente podían llevar a cabo una peregrinación delegada en nombre de otra persona por cada viaje. De esta manera, las autoridades de La Meca favorecían que los peregrinos volvieran a realizar el viaje por delegación, de lo que se deduce un interés añadido por incrementar los ingresos de la mezquita de La Meca - y posiblemente de Medina- a través de la emisión de nuevos certificados de peregrinación. Así se mantenía el flujo constante de peregrinos y se evitaba que un solo individuo llevase a cabo el ritual en nombre de varias personas en un único viaje. Según Niebuhr, al menos 
durante el siglo XVIII, ésta fue la forma de controlar la delegación y prevenir la impostura de peregrinos profesionales. Su relato es, por tanto, una confirmación de las noticias que tenemos sobre este tipo de documentos y sus actores, atestiguadas por Chardin un siglo antes.

De mismo modo, gracias a las descripciones de Chardin, parece claro que los certificados fueron emitidos y adquiridos mayoritariamente en La Meca, cuestión sobre la que hasta ahora no había consenso en los principales estudios sobre el tema. Por lo que respecta a Medina, Niebuhr comenta que también compró a un turco una ilustración en la que figuraba la tumba del Profeta. Dicho acontecimiento se menciona en la descripción de su visita a Medina, por lo que existe la posibilidad de que también allí se emitieran certificados, en ese caso, de ziyāra. ${ }^{19}$ Por su parte, Chardin menciona que los peregrinos ši íes también adquirían estas "actas de viaje" en diferentes estaciones a través de la ruta de Bagdad, ${ }^{20}$ hecho que justifica los certificados con ilustraciones de otros lugares sagrados del islam ši $\iota^{i}$.

También se ha podido confirmar que, a su regreso, los peregrinos depositaban los certificados en las mezquitas, tal como suponían Dominique Sourdel y Janine Sourdel-Thomine (2006, 17-18) en sus estudios sobre los documentos hallados en la mezquita de Damasco. Sin embargo, no mencionan que éstos fueran colgados en sus muros, por lo que no es posible deducir de su relato si éstos fueron mostrados al público o tan sólo conservados en un archivo dentro de la mezquita (Carro Martín 2019, 145-157).

Por otra parte, las descripciones que Niebuhr y Burckhardt hacen del santuario de La Meca parecen coincidir en la incesante actividad comercial en su entrada principal. Ambos viajeros describen la venta de ilustraciones de La Meca y Medina

19 Las visitas a la tumba del Profeta en Medina eran una práctica habitual entre los peregrinos. Sobre la santidad de la ciudad en las fuentes árabes, véase Munt, 2014.

${ }^{20}$ Para una visión general de los certificados ši íes, véase Marzolph 2014, 207 242. 
y de certificados que acreditaban la peregrinación o la visita a los santuarios, lo que confirma su demanda entre los peregrinos musulmanes. Este panorama de vendedores aposentados en las inmediaciones de los santuarios también se atestigua en las descripciones de los viajeros musulmanes, como Ibn Ŷubayr (1145-1217), cuyo relato pone el foco en la venta de objetos para peregrinos en la entrada norte del santuario de La Meca, así como en los soportales (Ibn Ŷubayr 2007).

Por último, de los relatos de estos viajeros se puede concluir que el título de peregrino era meramente honorífico. El título de hâŷỹ al que aluden los viajeros nada tiene que ver con los certificados que conmemoraban la peregrinación delegada, que únicamente surgieron en el contexto legal de una práctica asociada a ella. Con su emisión, la administración se aseguraba el ingreso de una cantidad adicional y regulaba el cargo de los peregrinos "profesionales", quienes trataron de reconvertir una práctica piadosa como la delegación en un trabajo al uso.

\section{Referencias}

Adams, Issac. 1900. Persia by a Persian: Personal Experiences, Manners, Customs, Habits, Religious and Social Life in Persia. Londres: Elliot Stock.

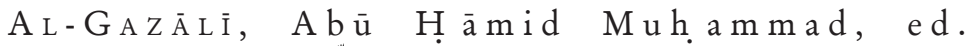
1356-1357/1937-1938. Iby äa

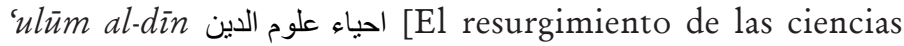
religiosas]. Vol. 1. El Cairo: Maṭba'at laŷnat našr al-Taqāfa alIslāmiyya مطبعة لجنة نشر الثقافة الاسلامية.

AL-MiṣRİ, Ahmad ibn Naqīb عمدة السالك .1994 . أحمد بن النقيب المصري 'Umdat al-sälik. Reliance of the Traveler: The Classic Manual of Islamic Sacred Law. Editado y traducido por Nuh Ha Mim Keller. Beltsville: Amana Publications.

Al-Ŷ́AZĪRI, 'Alī b. Yahyà A. علي بن يحيى بن القاسم الجزيري. 1998. Al-

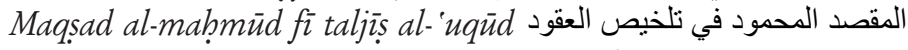
[Proyecto plausible de compendio de fórmulas notariales]. 
Editado por Asunción Ferreras. Madrid: Consejo Superior de Investigaciones Científicas.

Bauden, Frédéric. 2005. "Mamluk Era Documentary Studies: The State of the Art". Mamlūk Studies Review 9, núm. 1: 15-60. https://doi.org/10.6082/M1HD7SS3

BurcKHARDT, John Lewis. 1829. Travels in Arabia. 2 vols. Londres: A. J. Valpy.

CARRO MARTín, Sergio. 2019. Los certificados de peregrinación islámica delegada y la qubbat al-bुazna de Damasco: texto vs. contexto. eHumanista/IVITRA 15: 145-157. https://www.ehumanista. ucsb.edu/sites/default/files/sitefiles/ivitra/volume15/2.\%20 Carro.pdf

Chardin, Jean. 1711. Voyages de monsieur le chevalier Chardin en Perse et autres lieux de L'Orient. Vol. 2. Amsterdam: Chez Jean Louis de Lorme. https://gallica.bnf.fr/ark:/12148/bpt6k1050392t.image Eickelman, Dale F. y James Piscatori, eds. 1990. Muslim Travelers: Pilgrimage, Migration, and the Religious Imagination. Berkeley: University of California Press.

EsIn, Emel. 1983. "Un manuscrit illustré représentante les sanctuaires de la Mecque et Médine et le Dome du Mi'radj, à l'époque des sultans turcs Selim et Suleyman $1^{\text {er }}$ (H. 982-74/1516-66)”. Revue d'Histoire Maghrebine 10, núm. 31-32: 175-190. http://tekesin. org.tr/wp-content/uploads/2020/06/324.pdf

Graves, Margaret S. y Benoit Junod, eds. 2011. Architecture in Islamic Arts: Treasures of the Aga Khan Museum. Ginebra: Aga Khan Trust for Culture. https://www.academia.edu/7471091/Treasures_of the_Aga_Khan_Museum_Architecture_in_Islamic_arts

Hawting, Gerald R. 1990. “The 'Sacred Offices' of Mecca from Jāhiliyya to Islam". Jerusalem Studies in Arabic and Islam 13: 62-84.

HJÄRPE, Jan. 1998. “A Hajj Certificate from the Early 20th Century”. En Being Religious and Living through the Eyes: Studies in Religious Iconography and Iconology, A Celebratory Publication in Honour of Professor Jan Bergman, Faculty of Theology, Uppsala University, published on the occasion of his $65^{\text {th }}$ birthday, June 2, 1998, editado por Peter Schalk y Michael Stausberg, 197204. Upsala: Uppsala University.

IBN AL-'ATTAR. 2000. Formulario notarial y judicial andalusi del alfaqui y notario cordobés m. 399/1009. Traducido por Pedro Chal- 
meta y Marina Marugán. Madrid: Fundación Matritense del Notariado.

IBN RUŠD, ed. 1302/1982. Bidāyat al-muŷtahid wa-nihāyat al-muqtasid بداية المجتهد ونهاية المقتصد المبن [El comienzo de aquel que interpreta independientemente las fuentes y el final de aquel que desea limitarse]. Vol. 1. Beirut: Dār al-Ma'rifa دار المعرفة.

IBN ŶUBAYR, Muhammad b. Ahmad. 2007. A través del Oriente (Ribla). Estudio, traducción, notas e índices de Felipe Maíllo Salgado. Madrid: Alianza.

JaLīl IBN IsḤ̂̄Q al-Ǧundī. 1848. Précis de jurisprudence musulmane, ou

Principes de législation musulmane civile et religieuse, selon le rite mâlékite. Traducido por M. Perron. Vol. 2. París: Imprimerie nationale.

Katz, Marion. 2004. "The Hajj and the Study of Islamic Ritual”. Studia Islamica, núm. 98-99: 95-129. https://www.jstor.org/ stable/20059212

Marzolph, Ulrich. 2014. From Mecca to Mashhad: The Narrative of an Illustrated Shi'i Pilgrimage Scroll from the Qajar Period. Muqarnas 31, núm. 1: 207-242. https://doi.org/10.1163/22118993$00311 \mathrm{P} 09$

Marzolph, Ulrich. 2017. "The Niebuhr Scroll”. En Arrivals: The Life of the Royal Danish Expedition to Arabia 1767-2017, editado por Anne Haslund Hansen y traducido por Jane Rowley, 69-73. Copenhague: The National Museum of Denmark.

Mols, Luitgard. 2015. "Souvenir, Testimony, and Device for Instruction: Late Nineteenth- and Early Twentieth-Century Printed Hajj Certificates". En Hajj. Global Interactions through Pilgrimage, editado por Luitgard Mols y Marjo Buitelaar, 185212. Leiden: Sidestone Press.

Moufahim, Mona. 2013. "Religious Gift Giving: An Ethnographic Account of a Muslim Pilgrimage". Marketing Theory 13, núm. 4, 421-441. https://doi.org/10.1177/1470593113499698

MuḤaqdiq al-Hillī, Ja'far ibn al-Hasan. 1871. Droit Musulman : recueil de lois concernant les musulmans schyites. Traducido por Amédée Querry. Vol. 1. París: Imprimerie nationale.

MunT, Harry. 2014. The Holy City of Medina. Sacred Space in Early Islamic Arabia. Cambridge: Cambridge University Press. https:// doi.org/10.1017/CBO9781107323773 
NiebuHR, Carsten. 1792. Travels through Arabia and Other Countries in the East. Traducido por Robert Heron. Vol. 2. Edimburgo: Morison and Son.

Peters, Francis E. 1994. The Hajj: The Muslim Pilgrimage to Mecca and the Holy Places. Nueva Jersey: Princeton University Press.

RadiciotTi, Paolo y Arianna D’Ottone. 2008. "I frammenti della Qubbat ${ }^{\mathrm{t}}$ al-Hazna di Damasco. A proposito di una scoperta sottovalutata”. Nea Rhome. Rivista Di Ricerche Bizantinistiche, núm. 5: 45-74. http://nea-rhome-2017.uniroma2.it/wp-content/ uploads/2008/06/nr05_radiciotti.pdf

Raldi, Augustus. 1909. Christians at Mecca. Londres: William Heinemann.

REINAUd, Joseph Toussaint. 1828. Description des monumens musulmans du cabinet de M. Le Duc de Blacas. Vol. 2. París: L'imprimerie royale.

SOURDEL-Thomine, Janine y Jean-Michel Mouton. 2018a. "La pratique de la ziyāra par procuration dans la Syrie médiévale à partir de trois documents inédits". Der Islam 95, núm. 2: 507-523. https:// doi.org/10.1515/islam-2018-0032

Sourdel-Thomine, Jeanine y Jean-Michel Mouton. 2018b. "Pèlerinages par procuration à La Mecque et société médiévale damascaine (476/1084-710/1312)". Journal Asiatique 306, núm. 1: 3-29. https://doi.org/10.2143/JA.306.1.3284953

Sourdel-Thomine, Jeanine y Dominique Sourdel. 1964. "Nouveaux documents sur l'histoire religieuse et sociale de Damas au Moyen Âge”. Revue des études islamiques 32: 1-25. http://opac.regestaimperii.de/id/1494812

SOURDEL, Dominique y Jeanine Sourdel-Thomine. 1983. "Une collection médiévale de certificats de pèlerinage à la Mekke conservés à Istanbul. Les actes de la période seljoukide et bouride (jusqu'à 549/1154)". En Etudes mêdiévales et patrimoine turc : Volume publié à l'occasion du centième anniversaire de la naissance de Kemal Atatürk (Cultures et Civilisations Médiévales 1), editado por Oktay Aslanapa y Janine Sourdel, 167-273. París: Éditions $\mathrm{du}$ Centre national de la recherche scientifique.

SOURDEL, Dominique y Jeanine Sourdel-Thomine. 2001. "Certificats de pèlerinage par procuration à l'époque mamlouke”. Jerusalem Studies in Arabic and Islam, núm. 25: 212-233. 
SOURDEL, Dominique y Jeanine Sourdel-Thomine. 2006. Certificats de pèlerinage d'époque ayyoubide : contribution à l'bistoire de l'idéologie de l'islam au temps des croisades. París: Académie des inscriptions et belles-lettres.

TANINDI, Zeren. 1983. "Resimli bir Hac Vekâletnamesi”. Sanat Dünyamiz 28: 2-6.

WiTKAM, Jean Just. 2009. "Images of Makkah and Madinah in an Islamic Prayer Book". Hadeeth ad-Dar 30: 27-32.

Zwemer, Samuel Marinus. 1900. Arabia: The Cradle of Islam. Nueva York: Fleming H. Revell Company.

Sergio Carro Martín es licenciado en filología árabe por la Universidad de Salamanca y doctor en humanidades por la Universitat Pompeu Fabra de Barcelona. Ha desarrollado su actividad investigadora en el Consejo Superior de Investigaciones Científicas (CSIC-ILC) y la Universitat Pompeu Fabra, como miembro del Grupo de Investigación de Arqueología Mediterránea: Conexiones, Materialidades y Escritura. Desde 2011 participa en ese proyecto gestionando las bases de datos de las colecciones papirológicas en España. Sus principales líneas de investigación son el derecho islámico, la papirología árabe y la cultura material en el mundo árabe e islámico.

https://orcid.org/0000-0002-9455-3567 sergio.carro@upf.edu 